\title{
CHEMICAL INCIDENTS RESULTED IN HAZARDOUS SUBSTANCES RELEASES IN THE CONTEXT OF HUMAN HEALTH HAZARDS
} ANNA PAŁASZEWSKA-TKACZ, SŁAWOMIR CZERCZAK, and KATARZYNA KONIECZKO

\author{
Nofer Institute of Occupational Medicine, Łódź, Poland \\ Department of Chemical Safety
}

\begin{abstract}
Objectives: The research purpose was to analyze data concerning chemical incidents in Poland collected in 1999-2009 in terms of health hazards. Material and Methods: The data was obtained, using multimodal information technology (IT) system, from chemical incidents reports prepared by rescuers at the scene. The final analysis covered sudden events associated with uncontrolled release of hazardous chemical substances or mixtures, which may potentially lead to human exposure. Releases of unidentified substances where emergency services took action to protect human health or environment were also included. Results: The number of analyzed chemical incidents in 1999-2009 was 2930 with more than 200 different substances released. The substances were classified into 13 groups of substances and mixtures posing analogous risks. Most common releases were connected with non-flammable corrosive liquids, including: hydrochloric acid (199 cases), sulfuric(VI) acid (131 cases), sodium and potassium hydroxides (69 cases), ammonia solution (52 cases) and butyric acid (32 cases). The next group were gases hazardous only due to physico-chemical properties, including: extremely flammable propane-butane (249 cases) and methane (79 cases). There was no statistically significant trend associated with the total number of incidents. Only with the number of incidents with flammable corrosive, toxic and/or harmful liquids, the regression analysis revealed a statistically significant downward trend. The number of victims reported was 1997, including 1092 children and 18 fatalities. Conclusions: The number of people injured, number of incidents and the high 9th place of Poland in terms of the number of Seveso establishments, and 4 times higher number of hazardous industrial establishments not covered by the Seveso Directive justify the need for systematic analysis of hazards and their proper identification. It is advisable enhance health risk assessment, both qualitative and quantitative, by slight modification of the data collection system so as to enable the determination of released chemical concentration and exposed populations. Int J Occup Med Environ Health 2017;30(1):95-110
\end{abstract}

Key words:

Environmental health, Public health implications, Health risk assessment, Chemical hazards, Chemical incidents, Hazardous chemical releases

\section{INTRODUCTION}

Chemical incidents involving the release of substances hazardous to human health may carry the risk of serious adverse health and economic effects due to its nature and frequently unpredictable consequences. According to data estimated by the International Federation of Red Cross and Red Crescent Societies (IFRC), in 19982007 there were nearly 3200 technological disasters involving the release of chemicals all over the world, which resulted in approximately 100000 people killed and

Funding: the study was funded by a grant from the Nofer Institute of Occupational Medicine (IMP No. 24.9.) "Analysis of chemical accidents in Poland in the period of 1999-2009 in the context of health risk assessment possibility." Grant manager: Anna Pałaszewska-Tkacz, Ph.D.

Received: July 9, 2015. Accepted: January 13, 2016.

Corresponding author: A. Pałaszewska-Tkacz, Nofer Institute of Occupational Medicine, Department of Chemical Safety, św. Teresy 8, 91-348 Łódź, Poland (e-mail: apalasz@imp.lodz.pl). 
nearly 2000000 injured [1]. Chemical disasters taking place in Europe over the last few decades have contributed to development and publication of the Council Directive 82/501/EEC of 24 June 1982 on the major-accident hazards of certain industrial activities, popularly known as the Seveso Directive [2]; Seveso is the name of a town in Italy where the release of about 2 tons of chemicals, including toxic 2,3,7,8-tetrachlorodibenzo-p-dioxin (TCDD), took place on July 10, 1976 [3].

The provisions of the Seveso Directive and its amendments in 1996 (Seveso II) and 2012 (Seveso III) are intended to implement consistent regulations reducing the likelihood and mitigating the consequences of major chemical accidents within the European Union (EU) [4,5]. Provisions in question mainly relate to obligations connected with risk management in enterprises of increased or high risk of industrial accident (so called lower-tier and upper-tier establishments), the latter including those in which dangerous substances listed in Annex I to the Seveso III Directive are used in specified amounts. Currently in the EU, more than 10000 plants fall under these provisions [6]. In Poland in 2009-2011 there were 193 (2009), 186 (2010), 194 (2011) lower-tier establishments and 167 (2009), 171 (2010) and 166 (2011) upper-tier establishments, whereby Poland was listed as 9th among the European countries with highest chemical accident risk $[7,8]$.

According to data collected by the National Headquarters of the State Fire Service (Komenda Główna Państwowej Straży Pożarnej) and the Chief Inspectorate of Environmental Protection (Główny Inspektorat Ochrony Środowiska), in Poland there are approximately 4 times more plants posing threat of serious industrial accidents that do not meet the criteria qualifying them as lower-tier or upper-tier establishments (so called non-Seveso establishments) $[9,10]$. The legal requirements for safety management in nonSeveso establishments are much less restrictive than in lower-tier and upper-tier establishments, which may result in a greater probability of a chemical incident occurrence.
According to registers of the major accidents and the events with signs of major accidents run by the Inspectorate for Environmental Protection [11], in 1999-2009 there were approximately 150 such events annually, including those associated with fires and explosions. That number represents only a certain percentage of events associated with the release of hazardous chemicals in which the State Fire Service intervention was necessary. Chemical incidents not meeting the definition of a major accident are more common for obvious reasons and, because of less spectacular effects, are not regularly analyzed in the context of risks they offer to human health.

It was one of the reasons why in 2005-2010 the Nofer Institute of Occupational Medicine (NIOM), Łódź, Poland, started the cooperation with the National Centre for Rescue Coordination and Civil Protection (Krajowe Centrum Koordynacji Ratownictwa i Ochrony Ludności - KCKRiOL) located in the National Headquarters of the State Fire Service, involving exchange of information on the events associated with release or threat of release of hazardous substances for the purpose of assessing the health risks associated with exposure to hazardous chemicals released in uncontrolled manner.

Simultaneously, the NIOM cooperated with the US Agency for Toxic Substances and Disease Registry (ATSDR), in the area of the Hazardous Substances Emergency Events Surveillance system (HSEES) (now NTSIP - The National Toxic Substance Incidents Program).

The collaboration between the NIOM, KCKRiOL and ATSDR has resulted in the development at NIOM of the database on chemical incidents, which is unique in terms of the scope of information collected.

In contrast to the events that meet the definition of a major chemical accident specified in the provisions of Polish law implementing the Seveso Directives, there are no strict regulations connected with "less serious" chemical incidents, aimed at reducing the probability of their occurrence and minimizing their potential effects. 
In available literature there are only few analyses of individual cases prepared mainly in the context of technical capabilities of emergency services, but there is no reliable assessment of general population health risk connected with exposure attributable to uncontrolled leakage of hazardous substances. Developing the database in the NIOM, containing selected and verified information about chemical incidents enabled the identification of risks to health and the environment resulting from the release of hazardous substances in an uncontrolled manner.

The article presents the analysis of data on chemical incidents in Poland collected in 1999-2009 with particular reference to hazards they offer to human health.

\section{MATERIAL AND METHODS}

The scope of activities and the number of rescue operations performed by fire brigades in Poland show that the data collected by the National Centre for Rescue Coordination and Civil Protection is sufficient to illustrate the actual situation in Poland in the sphere of chemical incidents. Moreover, the collected data concerns all incidents, describing not only releases that occurred in industrial sites (including Seveso and non-Seveso plants) or transport but also in municipal settings. Thereby the data provides a solid basis for the analysis of spatial and temporal distribution of chemical incidents in Poland in 1999-2009 in the context of health hazards. The analysis of data in question was carried out in stages by: - obtaining and verifying data from the chemical incident reports prepared by rescuers at the scene, using a multimodal information technology (IT) system designed to support the work of state fire service,

- creation of a database containing systematic and clear information about the chemical incidents in the scope enabling the analyzes aimed at health risk assessment, with application of some solutions used in IT system for the HSEES provided by the ATSDR,

- qualitative and quantitative analysis of the collected data in the context of human health hazards.
Reports of chemical incidents that took place in Poland between 1999 and 2009, generated using the mentioned IT software designed for use by local and national firefighter headquarters were analyzed. A preliminary analysis of 32030 events connected with the release of chemicals, taking place in Poland in 1999-2009 showed that $9.14 \%$ (2930) incidents met the adopted definition of a chemical incident. The definition covered sudden events associated with uncontrolled release or threat of release of chemical substances or mixtures hazardous to human health, which may potentially lead to human exposure (excluding fires and explosions).

The verification process also included events related to the release of unidentified substances or mixtures where emergency services had taken action to protect human health or environment. Chemical substances or mixtures which fulfill the classification criteria relating to the hazards arising from physico-chemical properties, toxicological or ecotoxicological profile defined in the Classification, Labelling and Packaging (CLP) Regulation [12] and substances or mixtures unidentified during rescue operations, were regarded as representing hazardous substances (alternatively called dangerous substances). Incidents connected with the release of petroleum derivatives are not included, mainly due to the significant number of traffic accidents that could give a distorted picture of the true situation.

Because of the large number of substances released or threatened to be released in chemical incidents during considered period (> 200 different substances), they were classified into 13 groups of substances and mixtures posing analogous or similar risks. Categorizing of substances was made taking into account the criteria for classification of substances and mixtures described in the CLP Regulation [12], guidelines on chemical safety assessment for the Registration, Evaluation, Authorisation and Restriction of Chemicals (REACH) Regulation [13,14], as well as guide titled: "The 2008 emergency response - Guidebook" [15] (Table 1). 
Table 1. Hazardous chemical substances released or threatened to be released in chemical incidents in Poland, 1999-2009, by group of substance*

\begin{tabular}{ll}
\hline \multicolumn{1}{c}{ Group } & \\
\hline I & gases hazardous only due to physico-chemical properties \\
II & flammable gases, corrosive and/or toxic and hydrogen cyanide \\
III & non-flammable gases, corrosive and/or toxic and chlorates(I) and bromine \\
IV & irritant gases and other incapacitating gases including pepper gas/spray \\
V & flammable/oxidizing liquids and solids and fertilizers \\
VI & liquids and solids causing only the long-term effects or dangerous for the environment \\
VII & flammable irritant liquids and solids including glues, solvents and paints \\
VIII & non-flammable irritant liquids and solids \\
IX & non-flammable corrosive liquids \\
X & flammable corrosive liquids and solids \\
XI & flammable corrosive toxic and/or harmful liquids and solids \\
XII & non-flammable corrosive toxic and/or harmful liquids and solids \\
XIII & mercury \\
ND & substance unidentified during rescue actions \\
\hline
\end{tabular}

* Categorizing of substances was made taking into account the criteria for classification of substances and mixtures described in the Classification, Labelling and Packaging (CLP) Regulation [12], guidelines on chemical safety assessment for the Registration, Evaluation, Authorisation and Restriction of Chemicals (REACH) Regulation [13,14], as well as guide titled: "The 2008 emergency response - Guidebook" [15].

ND - no data.

\section{RESULTS}

\section{Spatial and temporal distribution}

In 1999-2009, among 2930 incidents, in 89\% (2606 incidents) the hazardous substance was actually released, while in 324 cases $(11 \%)$ there was a threat of release. In that period, the average of 266 incidents were reported annually, with the highest number of incidents in 2004 (308 events), and the lowest in 2009 (223 events) (Figure 1).

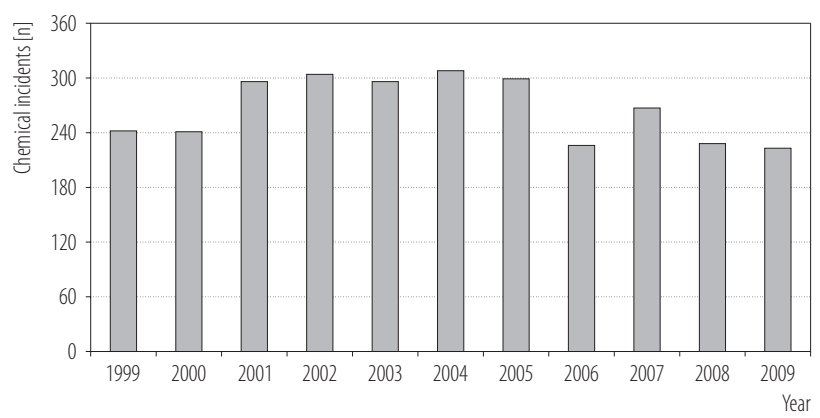

Fig. 1. Chemical incidents in Poland, 1999-2009
No statistically significant trend was observed $\left(\mathrm{r}^{2}=0.1\right.$, $\mathrm{p}>0.31$ ) for the number of chemical incidents during the considered period (Figure 2).

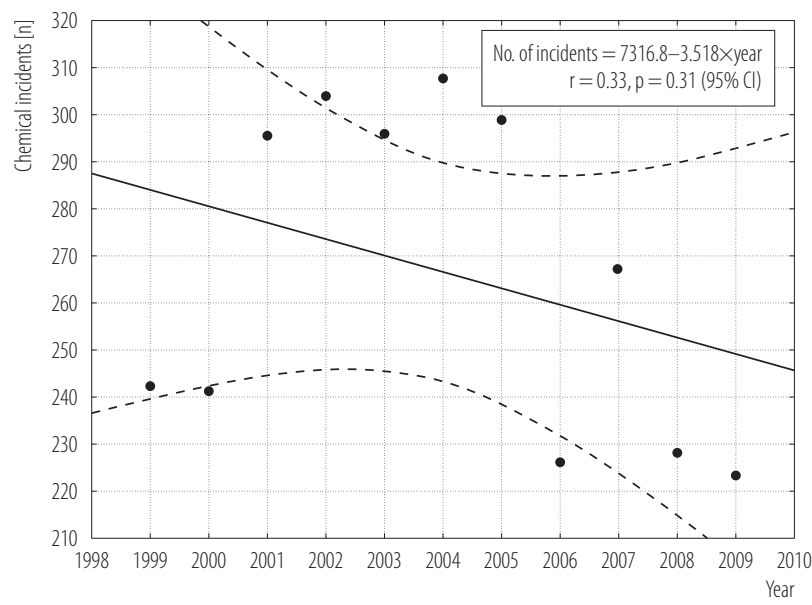

CI - confidence interval.

Fig. 2. Trend line for chemical incidents in Poland, 1999-2009 
Taking into account the spatial distribution, the highest incidence of the analyzed events was in Mazowieckie voivodeship, where there were 503 incidents connected with the release of hazardous substances, and Śląskie voivodeship (397 cases). In the Figure 3, the number of incidents is compared to the spatial distribution of the industrial establishments posing risk of major industrial accident on the basis of the Inspectorate for Environmental Protection and State Fire Service data [9].

Mazowieckie and Śląskie voivodeships are also those with the highest number of the industrial establishments posing risk of the accident, including Seveso plants and so called non-Seveso establishments. Over 200 incidents were recorded in each of Małopolskie, Dolnośląskie, and Kujawsko-Pomorskie voivodeships in the considered period. Fewer than 100 were reported in each of Świętokrzyskie, Warmińsko-Mazurskie, Opolskie and Podkarpackie voivodeships, the corresponding numbers being 85, 60, 58 and 53 incidents, respectively. The number of incidents in individual counties was also analyzed. Most chemical incidents were reported in the county towns including: Warszawa (245 incidents), Kraków (109 incidents), Łódź (86 incidents) and Wrocław (82 incidents). In Toruń, Bydgoszcz, Poznań, Gdańsk and

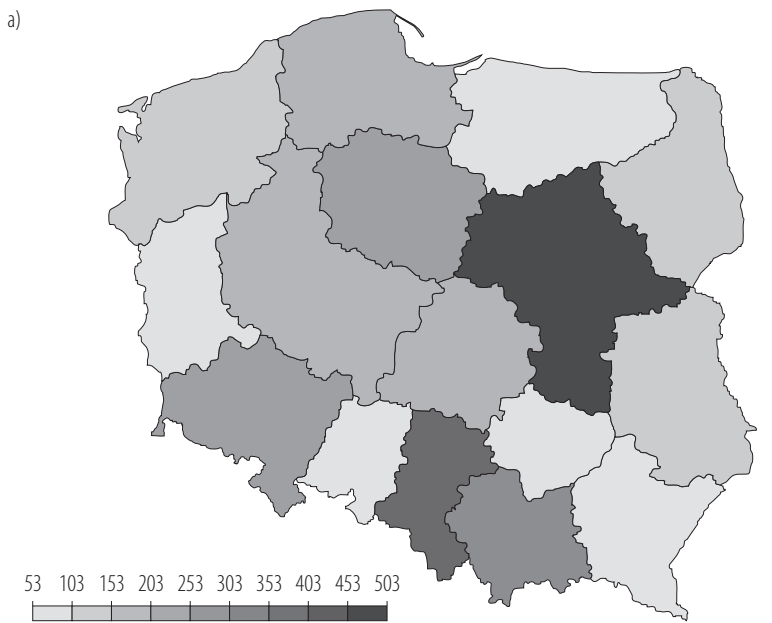

Gdynia 50-57 chemical incidents occurred in the considered period. In 33 counties, no case of a chemical incident was reported in 1999-2009 (Figure 3).

Relating the number of chemical incidents to the population number of the province, the largest number of events per 100000 inhabitants were recorded in Podlaskie (11.5), Kujawsko-Pomorskie (11) and Lubuskie (10.1), while the smallest in Podkarpackie (2.5) and WarmińskoMazurskie (4.2). For the total of Poland, 7.7 chemical incidents per 100000 inhabitants were reported in the period 1999-2009. The number of chemical incidents in each voivodeship in 1999-2009 in relation to the number of inhabitants are presented in the Figure 4.

The analysis of the variation in the number of incidents between individual voivodeships in the considered period showed a statistically significant downward trend only in Małopolskie voivodeship (Figure 5). In other voivodeships, like in the whole of Poland, there were no statistically significant changes in the number of incidents with time.

Taking into consideration the type of the events, $67 \%$ occurred within stationary objects (fixed facility events), while $23 \%$ were directly related to the transport of hazardous chemicals (transportation events). In 19992009 among the facilities where the chemical incidents

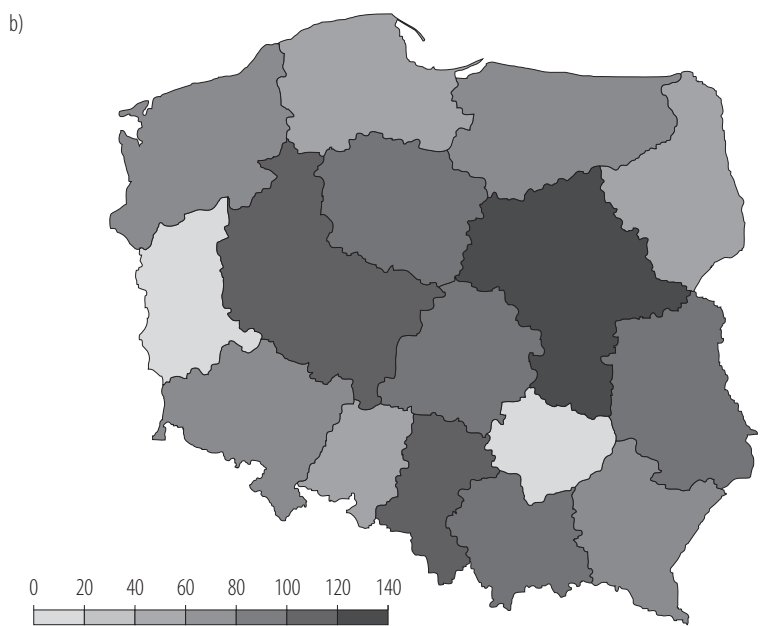

Fig. 3. a) Chemical incidents in Poland, 1999-2009, in comparison with b) the industrial establishments posing risk of major industrial accident, by voivodeship 


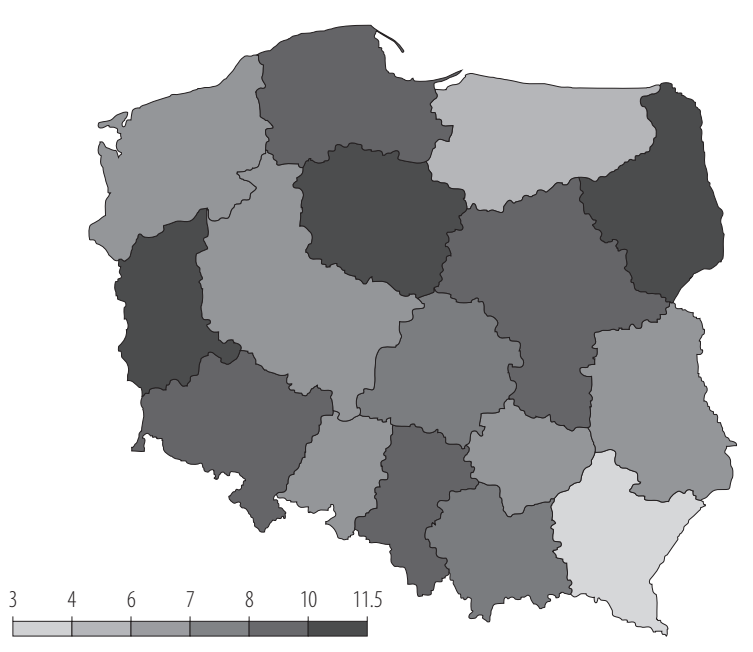

Fig. 4. Chemical incidents per 100000 inhabitants in Poland, 1999-2009, by voivodeship

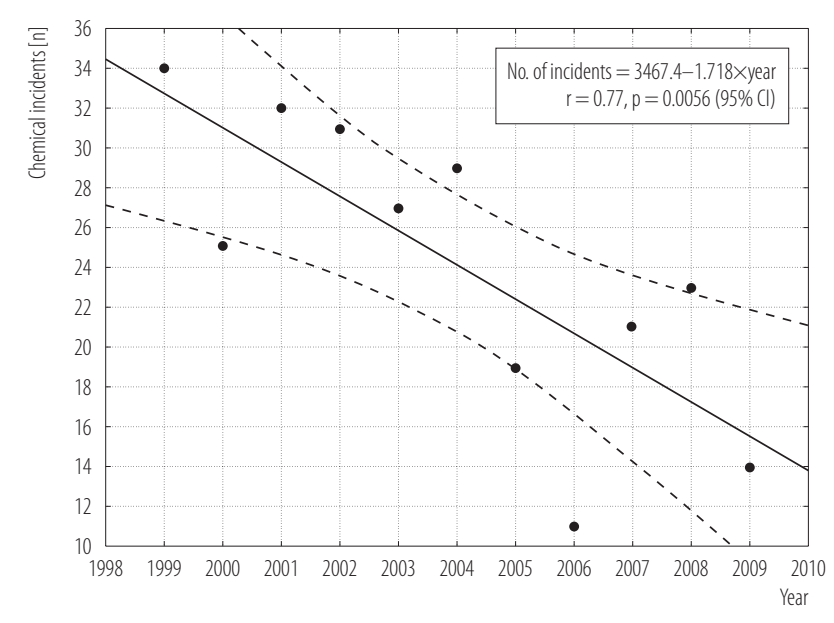

CI - confidence interval.

Fig. 5. Trend line for the chemical incidents in Małopolskie voivodeship, Poland, 1999-2009

occurred most often were public buildings (469 cases, $16 \%$ ), mainly buildings for educational purposes (schools, kindergartens, etc.) (221 incidents). The smallest percentage of chemical incidents in this period took place in forests and agricultural areas (18, 0.6\% and 32,1.1\%, respectively). Places denoted as "other" in Figure 6, where $25 \%$ of the incidents occurred, included mostly sides of the roads and rail trails where the released substance was identified and no particular means of

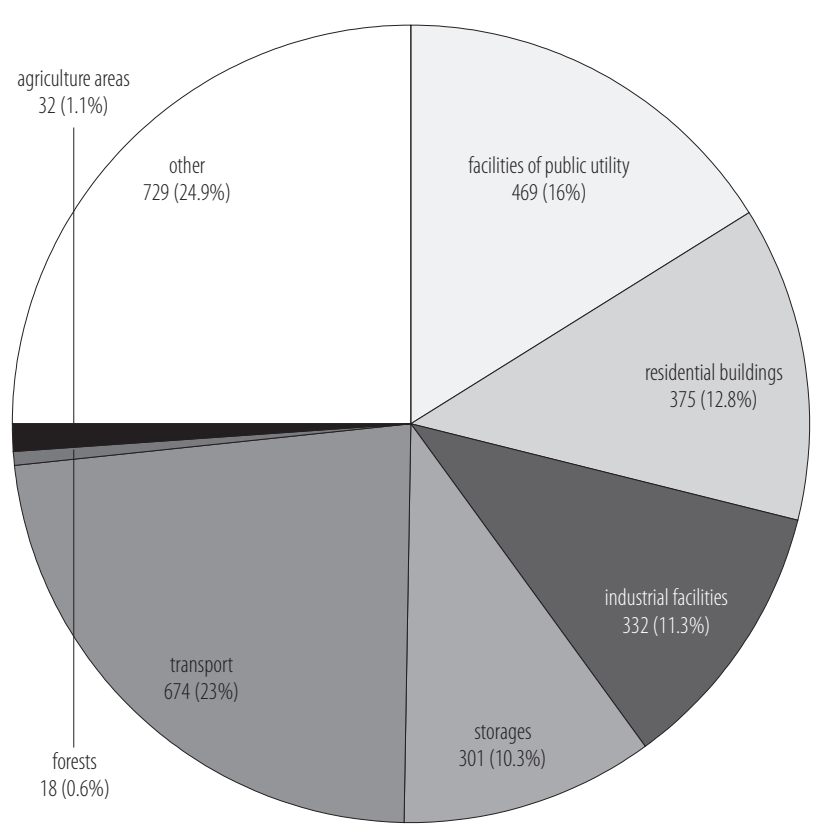

Fig. 6. Chemical incidents in Poland, 1999-2009, by place of substance release

transport were present. Many incidents included in this group took place also in garbage dumps (Figure 6).

\section{Type of chemical substances released}

In 2930 chemical incidents that occurred in Poland between 1999 and 2009, over 200 different hazardous substances or mixtures were released. Due to the large number, released substances and mixtures were classified into groups of agents posing analogous or similar threats. The most commonly released groups of substances included non-flammable corrosive liquids (635 cases), mainly hydrochloric acid (199 cases), and gases hazardous only due to physico-chemical properties (flammability, oxidizing properties) (371 incidents), mainly propane-butane (249 cases) (Table 2, Figure 7).

The frequency of incidents involving the release of specific substances was also analyzed. Propane-butane, anhydrous ammonia, hydrochloric acid, sulfuric(VI) acid and mercury were the most frequently released chemicals. These 5 substances were reported in 34\% of all cases (991) in the considered period. Comparing the data on the most 
Table 2. Chemical incidents in Poland, 1999-2009, by group of substance*

\begin{tabular}{|c|c|}
\hline Group and most common substances & $\begin{array}{c}\text { Incidents } \\
{[\mathrm{n}]}\end{array}$ \\
\hline I. Gases hazardous only due to physico-chemical properties & 371 \\
\hline propane-butane, propane, butane & 249 \\
\hline II. Flammable gases, corrosive and/or toxic and hydrogen cyanide & 285 \\
\hline ammonia & 234 \\
\hline III. Non-flammable gases, corrosive and/or toxic and chlorates(I) and bromine & 132 \\
\hline chlorine & 65 \\
\hline IV. Irritant gases and other incapacitating gases including pepper gas/spray & 80 \\
\hline pepper gas/spray, etc. & 77 \\
\hline V. Flammable/oxidizing liquids and solids and fertilizers & 79 \\
\hline ethanol & 15 \\
\hline fertilizers & 21 \\
\hline VI. Liquids and solids causing only the long-term effects or dangerous for the environment & 35 \\
\hline tetrachloroethylene & 12 \\
\hline VII. Flammable irritant liquids and solids including glues, solvents and paints & 207 \\
\hline solvents and paints & 83 \\
\hline VIII. Non-flammable irritant liquids and solids & 34 \\
\hline calcium oxide and dihydroxide & 13 \\
\hline IX. Non-flammable corrosive liquids & 635 \\
\hline hydrochloric acid solution & 199 \\
\hline sulphuric(VI) acid solution and oleum & 131 \\
\hline sodium and potassium hydroxides & 69 \\
\hline ammonia solution & 52 \\
\hline X. Flammable corrosive liquids and solids & 107 \\
\hline nitric $(\mathrm{V})$ acid solution & 79 \\
\hline XI. Flammable corrosive toxic and/or harmful liquids and solids & 258 \\
\hline plant protection products & 66 \\
\hline XII. Non-flammable corrosive toxic and/or harmful liquids and solids & 140 \\
\hline formaldehyde solution & 22 \\
\hline XIII. Mercury & 178 \\
\hline ND - substance unidentified during rescue actions & 389 \\
\hline
\end{tabular}

Abbreviations as in Table 1.

frequently released substances with the result of the research conducted by Gajek et al. [10] these are the same substances as those most frequently used in so called nonSeveso plants (Table 3).
Taking into account the type of released substances, the spatial distribution of chemical incidents in any of the voivodeships is not analogous with the distribution for the sum of all events in Poland (Figure 8). 
Table 3. Substances most frequently released in chemical incidents in Poland, 1999-2009

\begin{tabular}{lc}
\hline \multicolumn{1}{c}{ Substance } & $\begin{array}{c}\text { Incidents } \\
{[\mathrm{n}]}\end{array}$ \\
\hline Propane-butane, propane, butane & 249 \\
Anhydrous ammonia & 234 \\
Hydrochloric acid solution & 199 \\
Mercury & 178 \\
Sulphuric(VI) acid solution and oleum & 131 \\
Paints and solvents & 83 \\
Methane/natural gas & 79 \\
Nitric(V) acid solution & 79 \\
Pepper gas/spray, etc. & 77 \\
Sodium and potassium hydroxides & 69 \\
Plant protection products & 66 \\
Chlorine & 65 \\
Ammonia, aqueous solution & 52 \\
\hline
\end{tabular}

The release or threat of release of a hazardous substances in $60 \%$ of cases occurred inside, and less than $40 \%$ outside of building interiors. The places where the particular groups of substances were released most frequently are presented in the Table 4.

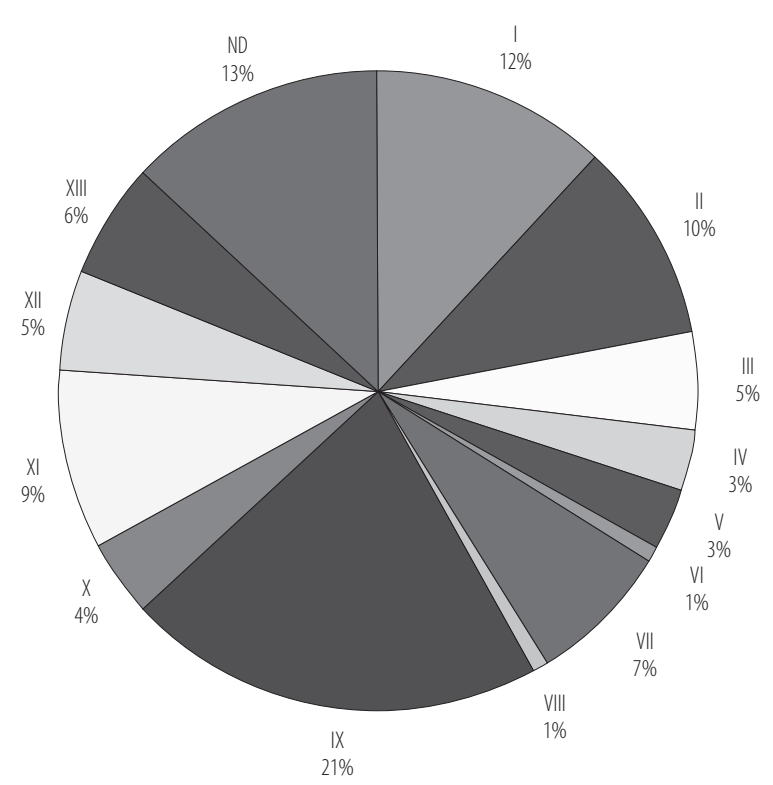

Groups as in Table 1.

Fig. 7. Chemical incidents in Poland, 1999-2009, by group of substance*

The regression analysis of the number of chemical incidents connected with the release of specific groups of substances over time was performed. The groups of substances and single substances which were released more than 150 times in the considered period 1999-2009 were analyzed:

Table 4. Chemical incidents in Poland, 1999-2009, by group of substance* and place of its release

Place of substance release

Chemical incidents in the subsequent subsegment groups

[n]

\begin{tabular}{lrrrrrrrrrrrrrr} 
& \multicolumn{1}{c}{ I } & \multicolumn{1}{c}{ II } & III & IV & V & VI & VII & VIII & \multicolumn{1}{c}{ IX } & X & XI & XII & XIII & ND \\
\hline Facilities of public utility & 19 & 48 & 26 & 45 & 4 & 3 & 19 & 2 & 100 & 21 & 27 & 32 & 26 & 97 \\
Residential buildings & 51 & 26 & 20 & 27 & 2 & 2 & 23 & 2 & 85 & 8 & 23 & 7 & 43 & 56 \\
Industrial facilities & 35 & 120 & 37 & 0 & 3 & 2 & 6 & 3 & 83 & 4 & 14 & 7 & 4 & 14 \\
Storages & 83 & 22 & 10 & 1 & 7 & 4 & 16 & 0 & 71 & 19 & 25 & 16 & 5 & 22 \\
During transport & 136 & 36 & 11 & 3 & 50 & 11 & 91 & 10 & 147 & 30 & 88 & 39 & 1 & 21 \\
Forests & 0 & 1 & 0 & 0 & 0 & 0 & 1 & 0 & 4 & 0 & 4 & 1 & 2 & 5 \\
Agriculture areas & 0 & 1 & 0 & 0 & 2 & 0 & 2 & 1 & 5 & 2 & 11 & 2 & 3 & 3 \\
Other & 47 & 31 & 28 & 4 & 11 & 13 & 49 & 16 & 140 & 23 & 66 & 36 & 94 & 171 \\
\hline
\end{tabular}

Groups as in Table 1. 

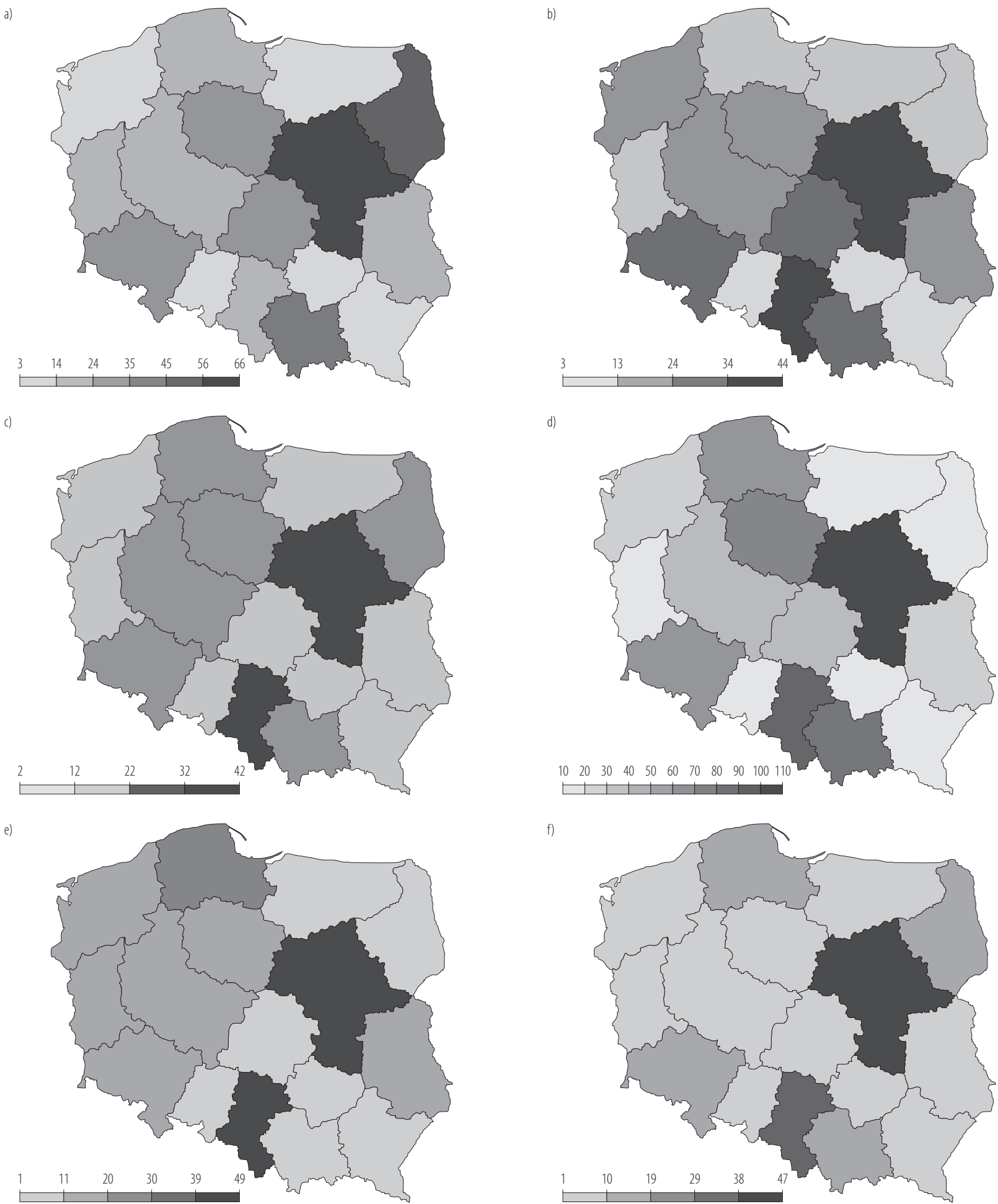

Groups as in Table 1.

Fig. 8. Chemical incidents in Poland, 1999-2009, by voivodeship and group of substance*: a) group I, b) group II, c) group VII, d) group IX, e) group XI, f) group XIII (groups with > 150 incidents) 


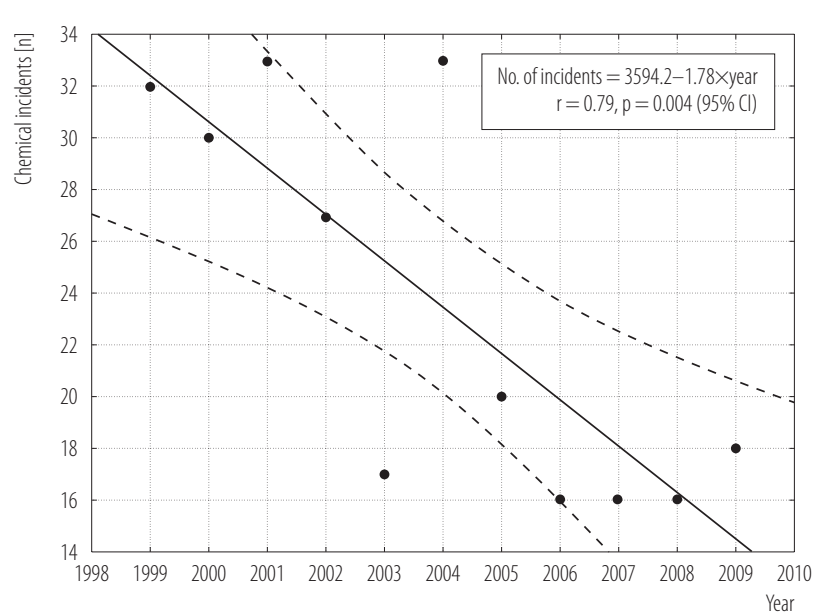

$\mathrm{CI}$ - confidence interval.

Fig. 9. Trend line for the chemical incidents with group XI substances (flammable corrosive toxic and/or harmful liquids and solids) in Poland, 1999-2009

- group I substances (371 cases) and propanebutane (249 cases),

- group II substances (285 cases) and anhydrous ammonia (234 cases),

- group VII substances (207 cases),

- group IX substances (635 cases) and hydrochloric acid (199 cases),

- group XI substances (258 cases),

- group XIII substances (178 cases).

No statistically significant dependence was observed ( $r<0.5, p>0.05$ ) in 1999-2009 for the number of chemical incidents in particular groups of substances and single substances apart from group XI. Only for group XI substances, a statistically significant downward trend was observed ( $<$ < 0.05) in 1999-2009 (Figure 9).

\section{The course of rescue operations}

In the analyzed period (1999-2009), rescue actions were carried out by an average of 12 rescuers, and the most common size of the rescue group was 6 people. Considering the duration time of rescue operations, $67 \%$ lasted from $1-5 \mathrm{~h}$ from the moment of reporting the event to

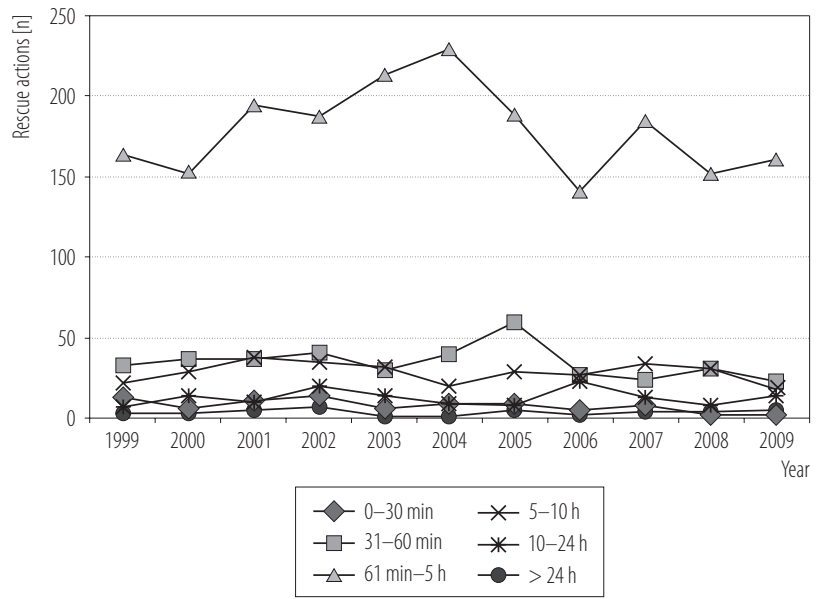

Fig. 10. Rescue actions of fire fighters at the scene of chemical incidents in Poland, 1999-2009, by action duration time

the return of the last rescue unit participating in the action (Figure 10).

Rescue operations most commonly performed by fire fighters at the scene included: securing the site of event (in $99.2 \%$ of cases); identification of chemicals released ( $71 \%$ of cases), and the collection, removal, cleaning of chemicals released (47.9\% of cases). Evacuation of people was performed in $15.5 \%$ of the events and the rescue activities directly related with premedical help were carried out in $5.5 \%$ of cases (Figure 11). Distribution for the whole period considered and each year is similar.

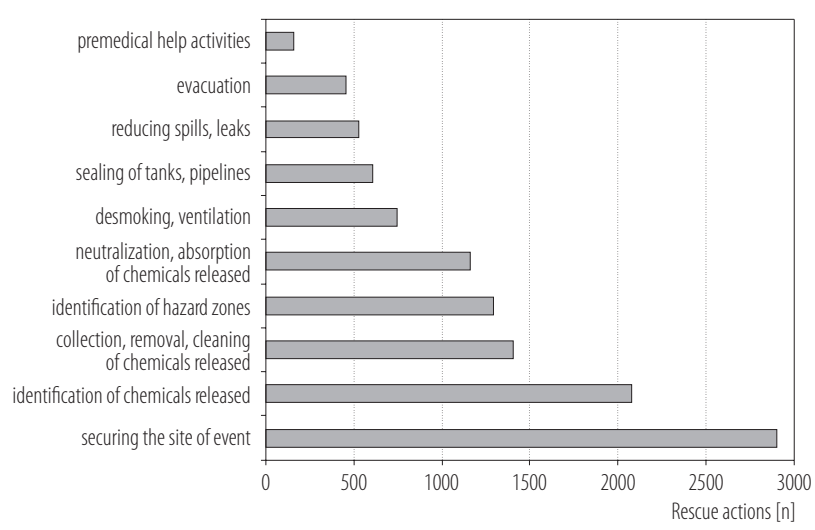

Fig. 11. Rescue activities most commonly taken by fire fighters at the scene of chemical incidents $(\mathrm{N}=2930)$ in Poland, 1999-2009 


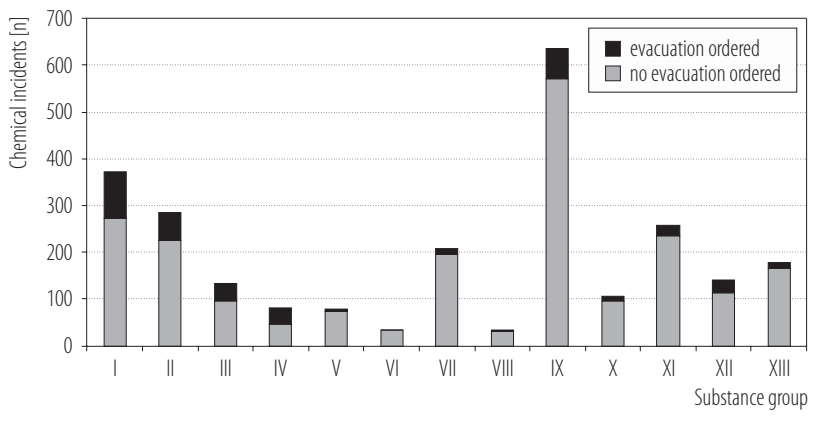

Groups as in Table 1.

Fig. 12. Chemical incidents in which evacuation was ordered, in Poland, 1999-2009, by group of substance*

Taking into account the type of the substance released, the evacuation was carried out most often (in $42.5 \%$ of cases) in the case of release of irritant and other incapacitating gases, including pepper gas/spray (group IV). This is due to the fact that the events related to the release of those gases took place in facilities of public utility, schools in particular. The Figure 12 shows the number of chemical incidents requiring evacuation of indoor space occupants, by the group of released substances.

\section{Victims}

From 1999 to 2009 in 369 chemical incidents (12.6\%) 1997 people were injured, and 18 of the injuries were fatal (Table 5, Figure 13). The largest group of victims were children (1092), who (excluding unidentified substances) were the most frequently exposed to irritant and other incapacitating gases, including pepper gas/spray (325 injured). These were most commonly releases connected with hoax or other intentional action, and the exposure occurred most often in schools. Similar

Table 5. Victims in chemical incidents in Poland, 1999-2009, by group of substance*

\begin{tabular}{lcccccccc}
\hline \multirow{2}{*}{$\begin{array}{c}\text { Group } \\
\text { of substance }\end{array}$} & \multicolumn{9}{c}{$\begin{array}{c}\text { Victims } \\
\text { [n (n of fatalities) }\end{array}$} & \multicolumn{2}{c}{$\begin{array}{c}\text { Incidents } \\
\text { with victims } \\
\text { [neneral } \\
\text { population }\end{array}$} & children & employees & $\begin{array}{c}\text { rescuers } \\
\text { (fire fighters) }\end{array}$ & $\begin{array}{c}\text { rescuers } \\
\text { (other) }\end{array}$ & not specified & total & [n] \\
\hline I & $20(2)$ & 2 & $31(2)$ & 3 & 0 & 4 & $60(4)$ & 33 \\
II & $16(1)$ & 7 & $76(3)$ & 4 & 5 & 8 & $116(4)$ & 39 \\
III & 24 & 16 & 57 & 3 & 0 & 14 & 114 & 30 \\
IV & 14 & 325 & 15 & 1 & 1 & 40 & 396 & 31 \\
V & 3 & 0 & $21(1)$ & 2 & 0 & 0 & $26(1)$ & 12 \\
VI & 0 & 0 & $36(1)$ & 0 & 4 & 5 & $45(1)$ & 6 \\
VII & 4 & 29 & $48(2)$ & 3 & 0 & 4 & $88(2)$ & 24 \\
VIII & $5(1)$ & 3 & 4 & 0 & 0 & 1 & $13(1)$ & 6 \\
IX & $27(1)$ & 52 & $84(1)$ & 5 & 2 & 7 & $177(2)$ & 53 \\
X & 1 & 0 & 18 & 0 & 0 & $7(1)$ & $26(1)$ & 8 \\
XI & $25(1)$ & 57 & $22(1)$ & 0 & 2 & 0 & $106(2)$ & 22 \\
XII & 2 & 11 & 25 & 4 & 2 & 10 & 54 & 19 \\
XIII & 1 & 26 & 2 & 0 & 0 & 1 & 30 & 6 \\
ND & 72 & 564 & 80 & 3 & 2 & 25 & 746 & 80 \\
Total & $214(6)$ & 1092 & $519(11)$ & 28 & 18 & $126(1)$ & $1997(18)$ & 369 \\
\hline
\end{tabular}

Groups as in Table 1. 


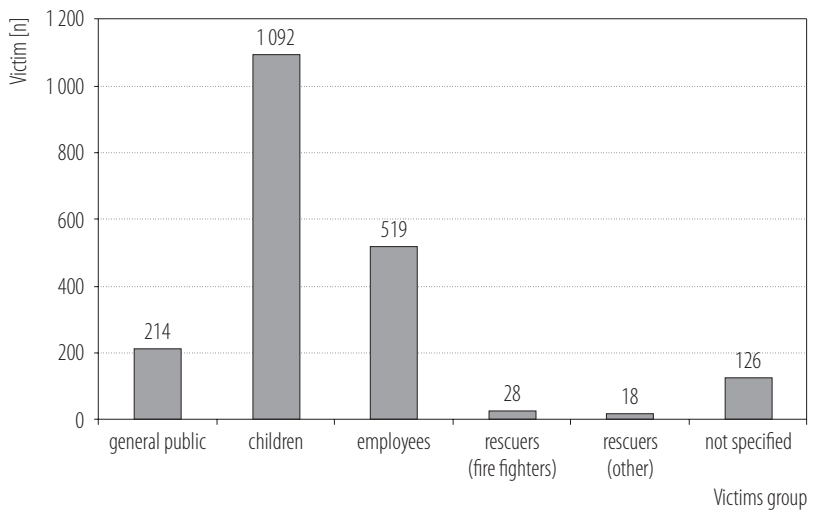

Fig. 13. Victims in chemical incidents in Poland, 1999-2009

observations were described by Wattigney et al. [16] who analyzed the data concerning the years 1996-2003 collected in the US under the HSEES project. The second largest group of victims were employees (519 injured), among whom the highest number of deaths was recorded (11, $61 \%$ of fatalities).

The largest group of injured employees was exposed to non-flammable corrosive liquids (group IX, 84 victims including 1 fatality) and flammable, corrosive and/ or toxic gases (group II, 76 victims including 3 fatalities). The third largest group of victims was the general population (214 victims including 6 fatalities), among whom most people were exposed to non-flammable corrosive liquids (group IX, 27 injured), flammable corrosive toxic and/ or harmful liquids and solids (group XI, 25 people), and gases hazardous only due to physico-chemical properties (group I, 20 injured). In the analyzed period, 46 rescuers (including 28 firefighters) were injured in chemical incidents, none fatally (Table 5, Figure 13).

\section{DISCUSSION}

On the basis of the analyses of data collected by the fire fighters during rescue operations in 1999-2009, over 200 different chemicals released or threatened to be released in chemical incidents were unambiguously identified. Identification of hazards posed by substances released was carried out on the basis of a harmonized classification criteria consistent with the CLP Regulation in force since 2008 [12]. In such cases where the unambiguous substance identification was not possible or substance did not have harmonized classification, hazard identification was made on the basis of the UN numbers [17], the analysis of descriptive characteristics made by rescuers and emergency procedures applied at the scene [15].

Hazard identification was possible in nearly $90 \%$ of the analyzed incidents. In 389 incidents, the type of substance released could not be determined. The absolute number of events connected with the release of unidentified substances and their percentage in the total annual number of incidents are presented in the Figure 14.

The regression analysis of number of chemical incidents connected with the release of the unidentified substances during the considered period did not demonstrate statistically significant trend $(r=0.106, p=0.757)$. The annual percentage of events in which the substance released was not specified in the total number of incidents remained at a similar level (8-18\%) in 1999-2009.

Because of the large number of substances released in chemical incidents in the analyzed period, categorization of substances into 13 groups of chemicals posing analogous or similar hazard for humans was made to ensure clear and transparent identification of threats (Table 1).

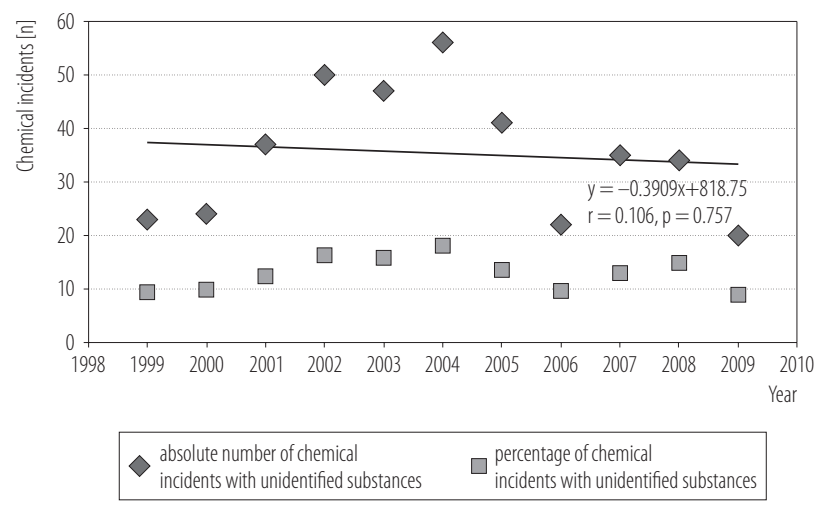

Fig. 14. Chemical incidents, in which identifying the released substance was not possible, in Poland, 1999-2009 
During the categorization of substances, also the potential possibility of exposure after release resulting from the general properties of the substance (i.e., state, volatility) was considered. Most common releases were connected with non-flammable corrosive liquids (group IX), including: hydrochloric acid (199 cases), sulfuric(VI) acid (131 cases), sodium and potassium hydroxides (69 cases), ammonia solution (52 cases) and butyric (32 cases), phosphoric(V) (14 cases) and formic (11 cases) acids.

The next group, by the number of incidents that occurred in the analyzed period, consisted of gases hazardous only due to their physico-chemical properties (group I), including: extremely flammable propane-butane (249 cases), methane (79 cases), propene, acetylene, hydrogen (6-19 cases) and oxygen (5 cases) classified as an oxidant that may cause or intensify fire.

The third group (group II) included flammable gases, corrosive and/or toxic substances with flammable, toxic if inhaled and corrosive anhydrous ammonia (234 cases) and extremely flammable hydrogen sulfide, which can be fatal if inhaled (24 incidents). Additionally, group II included hydrogen cyanide due to the nature of threats caused, i.e., classification of the liquid and its vapors as extremely flammable and fatal if inhaled.

Group XI - flammable corrosive toxic and/or harmful liquids and solids, was the fourth group of substances, taking into account the number of chemical incidents (258 cases). In this group among others were identified: highly flammable methanol, toxic if inhaled, in contact with skin and if swallowed (12 cases); corrosive white phosphorus, inhalation and ingestion of which may result in death (14 cases); tetrahydrothiophene, toxic if inhaled, in contact with skin and if swallowed (19 cases); corrosive hydrogen peroxide, toxic if inhaled and if swallowed (18 cases); xylene, toxic if inhaled and in contact with skin (12 cases) and plant protection products (66 cases).

In group VII - among flammable irritant liquids and solids there were identified: highly flammable benzene which is also skin and eye irritant (14 cases) or highly flammable toluene, which is also skin irritant (11 cases). These substances are also classified as causing adverse health effects as a result of long-term exposure, including the carcinogenic, mutagenic and reproductive toxicity. However, taking into account the specifics of a potential contact resulting from incidental release, the effects caused by long-term exposure were considered less important in the categorization process. In addition, group VII included adhesives, solvents and paints (83 events) for which the classification is usually similar.

Other groups of substances were released in $<200$ incidents in 1999-2009.

From the health risk perspective, significant is the fact that in described incidents nearly 2000 people were injured, including 18 fatalities. As it was mentioned already, the largest group of victims were children (1092), most frequently exposed to irritant gases and other incapacitating gases, including pepper gas/spray. The described situation resulted mainly from several incidents that were connected with hoax or similar intentional releases of chemicals at schools during lesson time when significant percentages of pupils/ students were inside the classroom.

Therefore, the need for the systematic analysis of threats and creating the possibility to estimate the health risks associated with chemical incidents seems reasonable. Currently there is no sufficiently detailed information regarding the concentrations of the substances released in chemical incidents and the precise identification of exposed population is not feasible; thus subsequent stages of risk assay, i.e., exposure and dose-response relationship assessment cannot be performed.

Usage of the measuring equipment after incident was declared in 948 events (32\%), but any (often inaccurate) information on the results of measurements are reported for approximately 490 events (17\%). Furthermore, the reports from the scene of event do not include either information on distance from the measuring points to the source of 
the leak, or potentially exposed groups of people, which makes it impossible to determine the actual level of exposure. For this reason, the final quantitative characteristics of the risk is not possible.

\section{CONCLUSIONS}

The scope of data collected at the scene of incident is sufficient to perform the analysis of spatial and temporal distribution of chemical incidents in Poland in the analyzed years 1999-2009, including among others: the number of people affected and the type of chemicals released. The presented analysis enable hazard identification associated with uncontrolled releases of chemical substances. Unequivocal identification of hazard was possible in $90 \%$ of incidents, but the lack of data on levels of exposure, concentration of the substances released and the precise definition of vulnerable population made it impossible to attempt full risk assessment.

The number of chemical incidents analyzed in the years 1999-2009 amounted to 2930 (an average of 266 per year). There was no statistically significant trend associated with the total number of incidents in subsequent years. Similarly, no statistically significant changes were observed in the number of incidents connected with the most commonly released substances, including propane-butane, anhydrous ammonia, hydrochloric and sulfuric acid and mercury. Only for group XI (flammable corrosive toxic and/ or harmful liquids and solids), the regression analysis revealed statistically significant downward trend $(\mathrm{p}<0.05)$ in the number of incidents in 1999-2009.

It is assumed that this situation may be the result of legal regulations connected with trade of chemicals. Substances included in group XI are very often subject to restrictions or authorization of production and use (e.g., chromium(VI) compounds, propylene oxide) as posing serious threats to health [13]. These regulations force entrepreneurs to reduce their use and seek for less harmful alternatives. Moreover, the use of plant protection products, which accounted for the largest proportion of compounds in group XI, was restricted by the national action plan aimed at reducing the risks associated with their use [18], which may also contribute to reducing the number of incidents involving those chemicals.

The number of victims reported in the analyzed period was 1997, including 1092 children and 18 fatalities. The number of people injured, not significantly decreasing the number of incidents, the high 9th place of Poland in terms of the number of Seveso establishments, and 4 times higher the number of hazardous industrial establishments not covered by the Seveso Directive, justify the need for systematic analysis of threats and their proper identification.

The current risk analysis would make it easier for the state administration representatives to better plan the effective preventive strategies, including appropriate allocation of capability package, which in turn would help reduce the number of people injured in incidents involving hazardous chemicals. Especially, due to the number of injured children, the verification of existing preventive procedures in this field at schools seems important. It would be recommended for the competent authorities to consider the additional actions aimed at raising awareness of students and school employees in the case of dangerous chemical release. It seems also advisable to ensure that more extensive health risk assessment, both qualitative and quantitative is made possible by modifying the structure of the reports from the scene of the incidents. Reliable characteristics of particular voivodeships of Poland in that respect, allowing to plan the effective preventive strategies and allocate capability package appropriately, could also result in reduction of rescue service costs.

\section{REFERENCES}

1. World Health Organization. Manual for the public health management of chemical incidents [Internet]. Geneva: The Organization; 2009 [cited 2013 May 15]. Available from: http://www.who.int/environmental_health_emergencies/publications/Manual_Chemical_Incidents/en. 
2. Council Directive 82/501/EEC of 24 June 1982 on the majoraccident hazards of certain industrial activities. Off J L 230, p. 1-18 (Aug 5, 1982).

3. Gajek A. [Seveso Directive III. Modifications of the procedures and elements of the system preventing major industrial accidents]. Przem Chem. 2013;92(5):602-5. Polish.

4. Council Directive 96/82/EC of 9 December 1996 on the control of major-accident hazards involving dangerous substances. Off J L 10, p. 13-33 (Jan 14, 1997).

5. Directive 2012/18/EU of the European Parliament and of the Council of 4 July 2012 on the control of major-accident hazards involving dangerous substances, amending and subsequently repealing Council Directive 96/82/EC Text with EEA relevance. Off J Eur Union L 197, p. 1-37 (Jul 24, 2012).

6. European Commission [Internet]. Brussels: The Commission [updated 2015 Apr 22; cited 2015 Jun 20]. Industrial accidents. The Seveso Directive - Prevention, preparedness and response. Available from: http://ec.europa.eu/environment/seveso.

7. Ministry of the Environment. [Report of Poland for the period 2009-2011 prepared according to Article 19 point 4 of Council Directive 96/82/EC on the control of major-accident hazards involving dangerous substances, fulfilling the criteria specified in Commission Decision of 19 Sept. 2008, No. K(2008) 5088] [Internet]. Warszawa: The Ministry, 2012 [cited 2014 May 20]. Available from: http://ec.europa.eu/environment/seveso/pdf/ reports/2009_11/countries/PL.pdf. Polish.

8. European Commission. Report on the Application in the Member States of Directive 96/82/EC on the control of major-accident hazards involving dangerous substances for the period 2009-2011. Brussels: The Commission; 2013 [cited 2014 May 20]. Available from: https://circabc.europa.eu/sd/ a/6e9ec4e2-89ae-404e-988c-1ff6effff1d6/1_EN_ACT_part1_ v7.pdf.

9. Gajek A, Michalik J, Rutkowska H, Janik P, Dziwulski D, Zając S. [Classification criteria of non-Seveso plants threatening the major industrial accidents applied by Inspection for Environmental Protection and State Fire Service]. Bezpiecz Pr. 2010;3:12-6. Polish.
10. Gajek A, Michalik J, Janik P, Dziwulski D, Zając S, Adamczyk A, et al. [Non-Seveso plants: Brand structure, plant types, hazardous chemical substances and the state of majoraccidents risk management]. Bezpiecz Pr. 2010;4:14-8. Polish.

11. Chief Inspectorate of Environmental Protection. [The events with the signs of major accidents and the major accidents in the period 1999-2009] [Internet]. Warszawa: The Inspectorate; 2013 [cited 2013 Jun 20]. Available from: http://www. gios.gov.pl/pl/o-urzedzie/25-powazne-awarie/106-wystepowanie-zdarzen-o-znamionach-powaznej-awarii. Polish.

12. Regulation (EC) No. 1272/2008 of the European Parliament and of the Council of 16 December 2008 on classification, labelling and packaging of substances and mixtures, amending and repealing Directives 67/548/EEC and 1999/45/EC, and amending Regulation (EC) No. 1907/2006 (Text with EEA relevance). Off J L 353, p. 1-1355 (Dec 31, 2008).

13. Regulation (EC) No. 1907/2006 of the European Parliament and of the Council of 18 December 2006 concerning the Registration, Evaluation, Authorisation and Restriction of Chemicals (REACH), establishing a European Chemicals Agency, amending Directive 1999/45/EC and repealing Council Regulation (EEC) No. 793/93 and Commission Regulation (EC) No. 1488/94 as well as Council Directive 76/769/EEC and Commission Directives 91/155/EEC, 93/67/ EEC, 93/105/EC and 2000/21/EC (Text with EEA relevance). Off J L 396, p. 1-520 (Dec 30, 2006), with Corrigendum Off J L 136, p. 3-280 (May 29, 2007).

14. European Chemicals Agency. Guidance on information requirements and chemical safety assessment. Part E: Risk characterisation. Version 2.0 [Internet]. Helsinki: The Agency; 2012 [cited 2015 Jun 20]. Available from: http://echa. europa.eu/documents/10162/13632/information_requirements_part_e_en.pdf.

15. Herian P, editor. [The 2008 emergency response - Guidebook] [Internet]. Warszawa: Chief Inspectorate of Environmental Protection [cited 2014 May 20]. Available from: http://www.gios.gov.pl/images/dokumenty/powazne_awarie/ Zasady_postepowania_ratowniczego_2008.pdf. Polish. 
16. Wattigney WA, Kaye WE, Orr MF. Acute hazardous substance releases resulting in adverse health consequences in children: Hazardous substances emergency events surveillance system, 1996-2003. J Environ Health. 2007 Nov;70(4):17-24.

17. Economic Commission for Europe, Committee on Inland Transport. European agreement concerning the international carriage of dangerous goods by road [Internet]. New York and Geneva: United Nations; 2012 [cited 2014 May 20]. Available from: http:/www.unece.org/trans/danger/publi/ adr/adr2013/13contentse.html.

18. [Announcement of the Minister of Agriculture and Rural Development of 6 May 2013 on the national action plan for reducing the risk connected with using plant protection products. Monit Pol 2013, No. 0, item 536]. Polish.

This work is available in Open Access model and licensed under a Creative Commons Attribution-NonCommercial 3.0 Poland License - http://creativecommons.org/ licenses/by-nc/3.0/pl/deed.en. 